\title{
Conducting experimental investigations of wind influence on high-rise constructions
}

\author{
Olga I. Poddaeva ${ }^{1}$, Anastasia N. Fedosova ${ }^{1}$, Pavel S. Churin ${ }^{1}$ and Julia S. Gribach ${ }^{1, *}$ \\ ${ }^{1}$ Moscow State University of Civil Engineering, Yaroslavskoe shosse, 26, Moscow, 129337, Russia
}

\begin{abstract}
The design of buildings with a height of more than 100 meters is accompanied by strict control in determining the external loads and the subsequent calculation of building structures, which is due to the uniqueness of these facilities. An important factor, the impact of which must be carefully studied at the stage of development of project documentation, is the wind. This work is devoted to the problem of studying the wind impact on buildings above 100 meters. In the article the technique of carrying out of experimental researches of wind influence on high-rise buildings and constructions, developed in the Educationalresearch-and-production laboratory on aerodynamic and aeroacoustic tests of building designs of NRU MGSU is presented. The publication contains a description of the main stages of the implementation of wind tunnel tests. The article presents the approbation of the methodology, based on the presented algorithm, on the example of a high-rise building under construction. This paper reflects the key requirements that are established at different stages of performing wind impact studies, as well as the results obtained, including the average values of the aerodynamic pressure coefficients, total forces and aerodynamic drag coefficients. Based on the results of the work, conclusions are presented.
\end{abstract}

\section{Introduction}

The construction of high-rise complexes is one of the priority directions in the field of construction in the modern world. Designing skyscrapers allows you to competently form the surrounding space, save territorial resources. The development and progression of technologies makes it possible to create unique architectural masterpieces (Figure 1), which have no analogues in the world [1-5].

However, the ratio of objects to the class of increased responsibility requires a competent approach to ensuring the reliability and safety of construction projects in the development of project documentation. One of the most influential external factors in the construction of high-rise buildings is the wind. Air flows often have an adverse effect on skyscrapers, which entails deformation of the structures [2,6-9]. In the current regulatory documents (SP 20.13330.2016 "Loads and impacts") it is established that in order to ensure the reliability and safety of high-rise buildings, a special assessment of the wind regime and

\footnotetext{
*Corresponding author: js-995@mail.ru
} 
aerodynamic parameters should be included in the design documentation, including the average and pulsation components of the estimated wind load, maximum values of wind load, resonance vortex excitation, etc. However, the determination of these values is possible only based on testing the layout in high-rise objects in wind tunnels of architectural and construction type $[3,4,10]$.

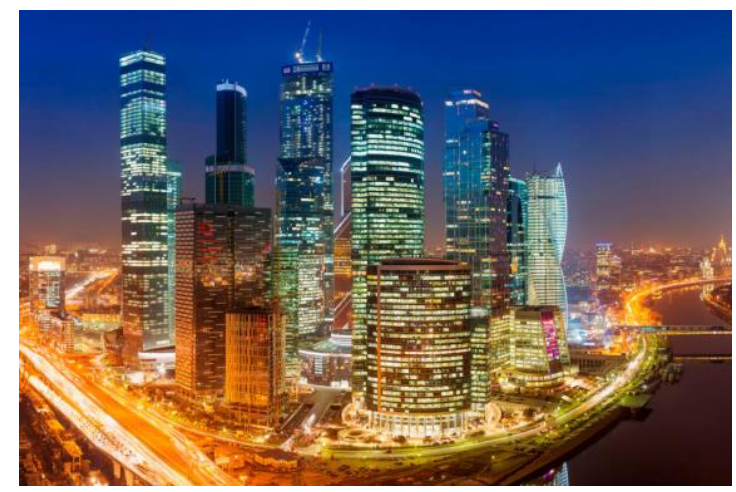

Fig. 1. High-rise buildings in Moscow (Moscow-city)

The purpose of this work is to describe the methodology for carrying out experimental studies of wind impact on high-rise buildings and structures to ensure their reliability and safety of objects, developed at the Research and Production Laboratory for Aerodynamic and Aeroacoustic Testing of Building Structures of the NRU MGSU [1-3], and its approbation on the example of a projected residential located in the city of Tyumen.

\section{Methods of research}

In this paper, a technique is presented for carrying out experimental studies of wind effects on high-rise buildings, developed and tested in the Educational and Research Laboratory for Aerodynamic and Aeroacoustic Testing of Building Structures of the Moscow State University of Civil Engineering.

In carrying out experimental studies of wind effects on buildings higher than 100 meters is to be executed the following steps:

- Climatic analysis of the territory, including the analysis of topographic and meteorological data: to assess wind loads, the nature of the variation in the average wind speed in height, the structure of atmospheric turbulence, the dependence of average velocities and turbulence on the roughness of the underlying surface of the terrain.

- Design and creation of the layout on a reduced scale, including an assessment of the geometric characteristics of the construction site, installation of measuring equipment for determining wind characteristics.

- Experimental research in a specialized wind tunnel and processing of the obtained results.

- Analysis of the received data, and development of conclusions and recommendations for ensuring the reliability and safety of structures.

Experimental studies are carried out on the basis of NRU MGSU. As a test bench was used a large gradient wind tunnel (Figure 2) of an architectural and construction type with a working zone length of $18.9 \mathrm{~m}$, which makes it possible to model the surface layer of the atmosphere. Figures and tables, as originals of good quality and well contrasted, are to be in their final form, ready for reproduction, pasted in the appropriate place in the text. Try to ensure that the size of the text in your figures is approximately the same size as the main text (10 point). Try to ensure that lines are no thinner than 0.25 point. 


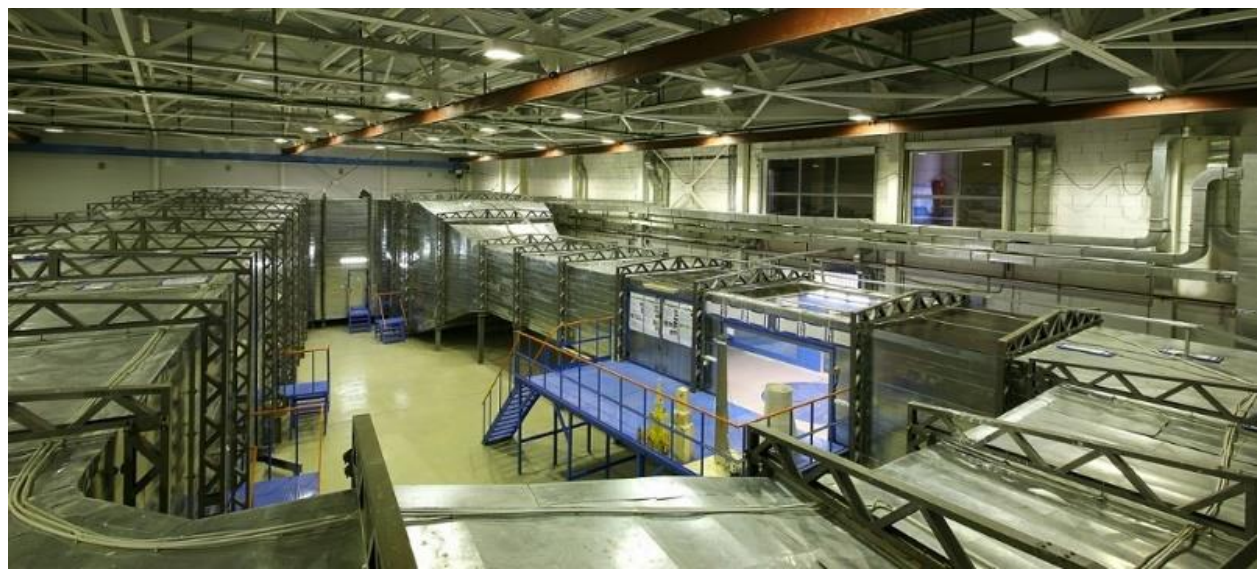

Fig. 2. Large Gradient Wind Tunnel NRU MGSU

\section{Approbation}

Approbation of this technique was carried out on the example of a projected multifunctional business center, located in Tyumen (Figure 3, a)). The building of the business center is a tower with a height of 110 meters. In terms of construction, the structure has the form of a rectangle with a rounded side with dimensions in the plan of 33.6 and 32.6 meters.

As already mentioned above, the climate analysis of the area is primarily carried out. Based on the climatic analysis, the type of terrain is selected in accordance with the requirements of SP 20.13330.2016, and the corresponding incident velocity profile is calculated. In this case, the type of development site corresponds to type "B".

a)

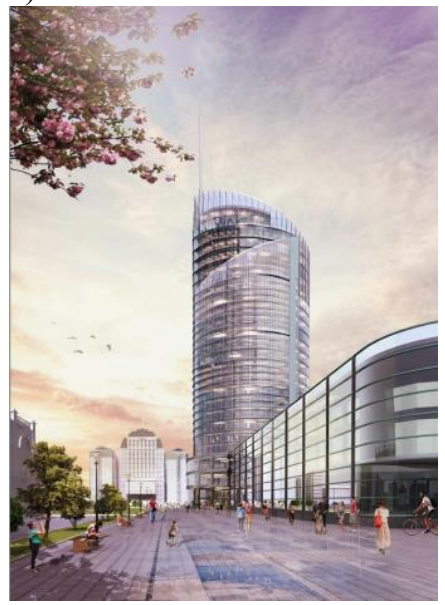

b)

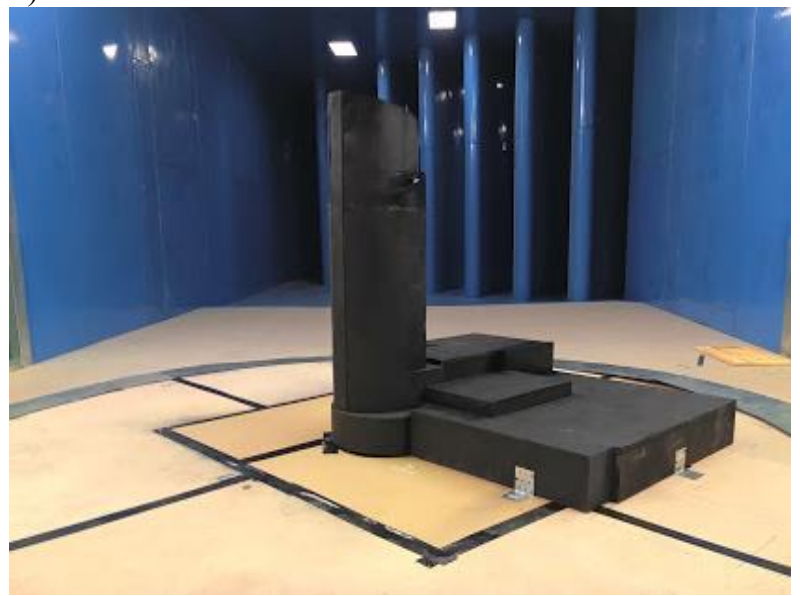

Fig. 3. a) Multifunctional business center, b) Model of a multifunctional business center

Design and production of the model on a reduced scale for experimental studies is performed. The scale of the layout is chosen from the compliance conditions established for the given tunnel of restrictions on the degree of cluttering of the cross section of the working part (in this case, M 1: 100) (Figure 3, b)) (GOST R 56728-2015) Buildings and 
structures Method for determining wind loads on the enclosing construction). To measure the flow velocity and pressure at characteristic points, a drainage system is installed (Fig. 4). Through the holes, the pressure is transferred through copper and silicone tubes to differential pressure sensors MPXV7002dp, the error in measuring pressure by these sensors, after their individual calibration, was $0.15 \%$.

The model of the investigated building was installed on a specialized turntable in the working area of the wind tunnel. After that, the installation was started and the air flow was fed to the model. The characteristic velocity of the air flow in the pipe is chosen to be sufficient to ensure self-similarity in the Reynolds number, when a further increase in speed does not lead to a significant change in the averaged values of the aerodynamic coefficients at the control points on the model (GOST R 56728-2015). During this series of tests, the wind speed in the working area was $15 \mathrm{~m} / \mathrm{s}$.

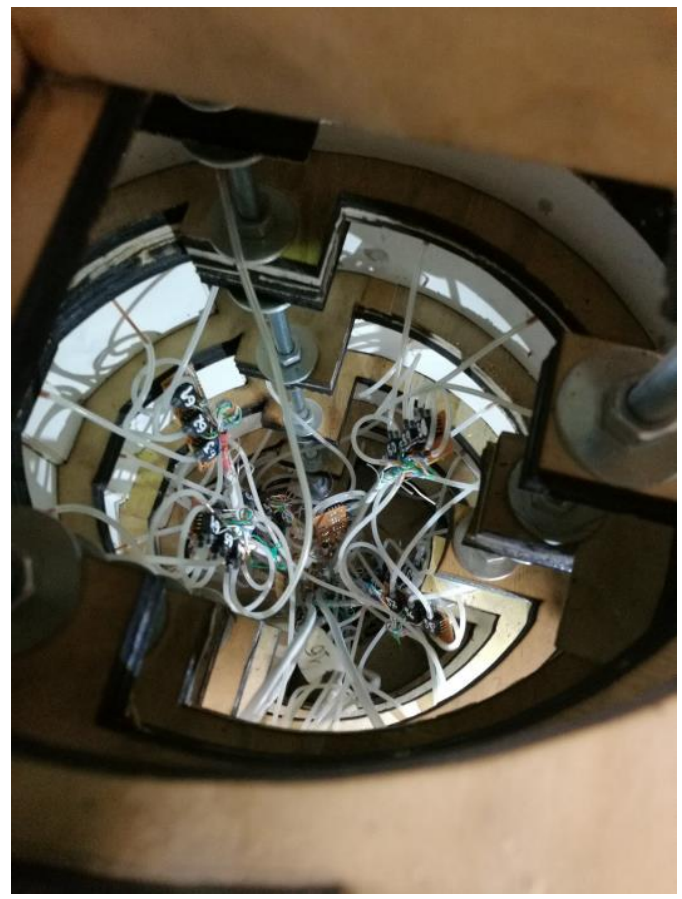

Fig. 4. Drainage system installation

\section{Results and discussion}

The result of the tests is the pattern of pressure distribution over the surface of the layout. Based on the obtained data, average values of aerodynamic pressure coefficients for various angles of attack of the wind from $0^{\circ}$ to $360^{\circ}$ are calculated with a definite step according to formula (1).

$$
C_{p}=(2 \times p) /(\rho \times \vartheta \wedge 2)
$$

where $\mathrm{Cp}$ - aerodynamic pressure coefficient

$\mathrm{p}$ - pressure (obtained by the experimental method)

$\rho$ - air density (at temperature $+20^{\circ} \quad \rho=1.2041 \mathrm{~kg} / \mathrm{m} 3$ )

$v-\operatorname{air} \operatorname{speed}(15 \mathrm{~m} / \mathrm{s})$ 
Similarly, the peak values of the aerodynamic pressure coefficients needed to calculate the peak component of the wind load on the enclosing structures and facade systems are calculated.

Aerodynamic drag coefficients relative to the $\mathrm{X}, \mathrm{Y}$ and $\mathrm{Z}$ axes $-\mathrm{Cx}, \mathrm{Cy}$ and $\mathrm{CMz}$ are calculated by means of six-component tensors and ATI DAQ F/T software (aerodynamic drag coefficients relative to the $\mathrm{X}, \mathrm{Y}$ and $\mathrm{Z}$ axes), graph of the dependence of the aerodynamic coefficients $\mathrm{Cx}, \mathrm{Cy}, \mathrm{Cmz}$ is plotted with a change in the angle of attack from $0^{\circ}$ to $345^{\circ}$ (Figure 5).

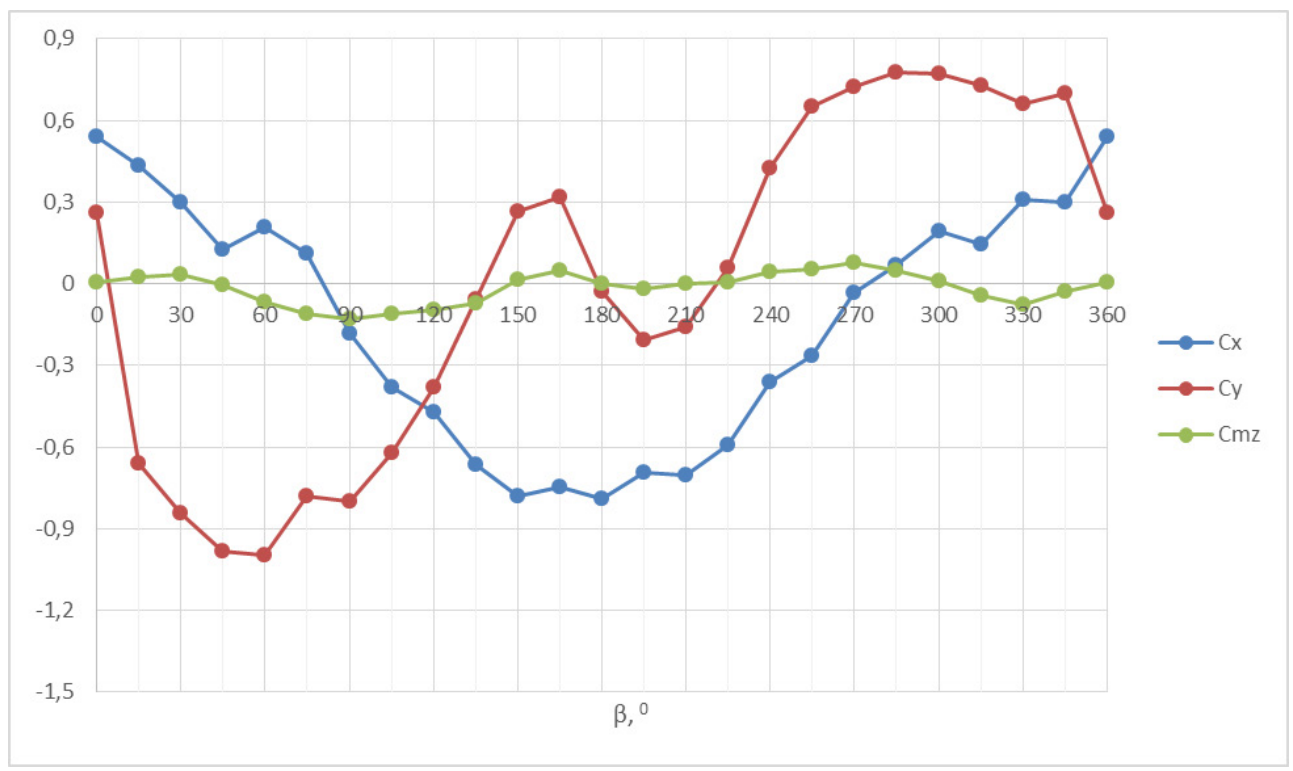

Fig. 5. Graph of the dependence of the aerodynamic coefficients $\mathrm{Cx}, \mathrm{Cy}, \mathrm{Cmz}$ with the angle of attack varying from $0^{\circ}$ to $345^{\circ}$

\section{Conclusions}

Based on the obtained results, it can be argued that the average and peak values of the aerodynamic coefficient $\mathrm{Cp}$ at control points on the surface of the layout, while the average values are in the range from 1.5 to -2.5 , and the peak values in the range from 2.5 to -4 . Zones with the maximum values of the peak aerodynamic coefficients are located on the lateral (in relation to the incoming wind) areas of the facades, in the characteristic zones of stalling the vortices from the structure.

The values of the dimensionless aerodynamic coefficients $\mathrm{Cx}, \mathrm{Cy}, \mathrm{Cmz}$ are determined with respect to the center of the base of the investigated object, while the maximum values of the coefficient $\mathrm{Cx}$ arise at the blowing angles $150^{\circ}$ and $180^{\circ}(\mathrm{Cx}=-0.78)$, the maximum values of the coefficient $\mathrm{Cy}$ arise at the blowing angles $45^{\circ}$ and $60^{\circ}(\mathrm{Cx}=-0.99)$. In general, the values obtained are fairly well correlated with the values of the aerodynamic coefficients given in SP 20.13330.2016, not exceeding them, which eliminates the need to develop specialized recommendations for structural modification.

\section{Acknowledgments}

The work was financial supported by the Ministry of Education and Science of the Russian Federation within the framework of the state \#7.6075.2017/BCh, Project «Investigation of 
the phenomena of aerodynamic instability of building structures in aeroelastic statement, including the development of an innovative methodology for analysing meteorologica data to refine the parameters of the wind load».

All tests were carried out using research equipment of The Head Regional Shared Research Facilities of the Moscow State University of Civil Engineering.

\section{References}

1. O.I. Poddaeva, J.S. Buslaeva, D.S. Gribach Physical model testing of wind effect on the high-rise, AMR, 1082, 246-249 (2015)

2. O.I. Poddaeva, J.S. Buslaeva, D.S. Gribach Experimental study of wind loads on a multifunctional high-rise residential complex, Vestnik Belgorodskogo gosudarstvennogo tehnologicheskogo universiteta im. VG Shuhova, 6, 58-62 (2015)

3. O.O. Egorychev, P.S. Churin Experimental study of wind loads on high-rise buildings, Zhilischnoe stroitelstvo, 6, 20 (2015)

4. Á.F. Saemundsson Wind effects on high rise buildings (2007)

5. J. D. Holmes Wind loading of structures, CRC press. (2015)

6. D. Čehel'ová, M. Janák, B. Bielek The impact of relative position of the high - rise buildings on the wind flow, AMM, 820 (2016)

7. Quan Yong, Gu Ming, Tamura Yukio Experimental evaluation of aerodynamic damping of square super high-rise buildings, WS, 8, 5, 309-324 (2005)

8. Huang Dongmei, Zhu Ledong,Ding Quanshun, Zhu Xue, Chen Wei Journal of Fluids and Structures, 69, 355-381 (2017)

9. M. Iancovici, M.A. Riley, F. Sadek, E. Simiu Wind effects on high-rise buildings: database-assisted design versus the high-frequency force-balance technique, ICWE (2017)

10. B. Yan, Q.S. Li Wind tunnel study of interference effects between twin super-tall buildings with aerodynamic modifications, JWEIA, 156, 129-145 (2016) 